\title{
Laboratory assessment of the status of Her-2/neu protein and oncogene in breast cancer specimens: comparison of immunohistochemistry assay with fluorescence in situ hybridisation assays
}

\author{
S Wang, M H Saboorian, E Frenkel, L Hynan, S T Gokaslan, R Ashfaq
}

\begin{abstract}
Aim-To evaluate the clinical usefulness of three commercially available assays for Her-2/neu oncogene and protein measurements. The Her-2/neu protein is overexpressed, mostly as a result of gene amplification, in $20-30 \%$ of human breast cancers, and has been shown to have prognostic and predictive value for treatment with chemotherapy or the new monoclonal antibody, Herceptin.

Methods-An immunohistochemistry (IHC) assay using the Dako polyclonal antibody A0485, which measures the Her$2 /$ neu protein, was compared with two new Food and Drug Administration (FDA) approved fluorescence in situ hybridisation (FISH) assays-INFORM ${ }^{\text {TM }}$ and PathVysion ${ }^{\mathrm{TM}}$, in a cohort of 52 formalin fixed, paraffin wax embedded breast tissues. These tissues were selected randomly from 84 consecutive infiltrating breast cancer specimens, which were first stratified according to the Her-2/neu protein levels as measured by IHC.
\end{abstract}

Results-The two FISH assays achieved a $98 \%$ concordance rate: 14 specimens (27\%) showed Her-2/neu gene amplification and 37 specimens $(71 \%)$ showed no Her-2/neu gene amplification. The PathVysion assay had certain advantages over the INFORM assay. In contrast, the IHC assay detected $\mathrm{Her}-2 /$ neu overexpression in a high percentage of cases, including 13 high positive specimens (25\%) and 13 medium positive specimens (25\%). Although 10 of these 13 IHC high positive specimens showed gene amplification by FISH, nine of 13 IHC medium positive specimens showed no gene amplification. Statistical analyses showed that the differences between IHC and FISH assays were primarily in the specimens with medium positive IHC, but negative FISH results. Conclusions-Because of the increasing importance of the Her-2/neu oncogene and oncoprotein in the clinical management of patients with breast cancer, the accurate and consistent evaluation of Her-2/neu status is crucial. This study suggests that the best approach is to combine both IHC and FISH assays; that is, to use the IHC assay as a triage step, followed by the PathVysion FISH assay to analyse the IHC medium and high positive cases. (F Clin Pathol 2000;53:374-381)
Keywords: Her-2/neu; breast cancer; fluorescence in situ hybridisation

Alterations in proto-oncogenes and tumour suppressor genes have been reported in human breast cancer. The Her-2/neu oncogene, also known as erbB-2, encodes one of the epithelial growth factor (EGF) receptors on the cell membrane, the functions of which include the stimulation of mammary epithelial cell proliferation. ${ }^{12}$ The Her-2/neu oncogene is overexpressed in $25-30 \%$ of breast cancers. ${ }^{3-5}$ In over $90 \%$ of these cases, Her- $2 /$ neu oncogene overexpression is attributed to Her$2 /$ neu gene amplification; that is, an increase in the number of gene copies in the cell, ${ }^{367}$ which results in raised concentrations of the corresponding mRNA and, ultimately, the Her2/neu oncoprotein. Other mechanisms, such as transcription activation, might be involved in the remaining cases.

Assessment of Her-2/neu status has gained increasing importance in the clinical management of patients with breast cancer. Her-2/neu overexpression/amplification in node positive cases is linked to poor prognosis; that is, shortened disease free interval and shorter survival time, and a similar linkage might also exist in node negative cases. ${ }^{348-11}$ Her-2/neu overexpression/amplification appears to be a significant predictor for the response to therapeutic agents. ${ }^{512} 13$ In addition, a humanised monoclonal antibody to the Her- 2 /neu protein, Herceptin (trastuzumab), has been shown to be an efficacious adjuvant therapeutic agent for patients with breast cancer who overexpress the Her-2/neu gene. ${ }^{14-16}$

Because it is a complex and unique issue, the assessment of Her-2/neu status is an excellent opportunity for pathologists to integrate cutting edge knowledge of molecular pathology into daily practice, and represents a formidable challenge to provide consistent and reliable information to clinicians. First, the evaluation of Her-2/neu status requires technically difficult quantitative assays. Her-2/neu alterations in breast cancer cause quantitative changesoverexpression of the protein as a result of gene amplification in most cases, as opposed to the qualitative changes (mutations or deletions) found for most other oncogenes and tumour suppressor genes. Second, status can be assessed either by measuring the concentration of Her-2/neu, which is directly involved in the pathogenesis of breast cancer, or gene amplification, which is thought to be the cause of 
Her-2/neu overexpression in most patients. Although various blotting assays, such as Southern blotting (which measures gene copy number), northern blotting (which measures mRNA values), or western blotting (which measures protein concentrations), have been used, these assays require large amounts of fresh tissue, and are thus not practical for most clinical settings. For routine formalin fixed, paraffin wax embedded breast tissue specimens, two types of assays are currently usedimmunohistochemistry (IHC) to measure the Her-2/neu protein and fluorescence in situ hybridisation (FISH) to measure Her-2/neu gene amplification (copy number). To date, the Food and Drug Administration (FDA) has approved three Her-2/neu assays for specific clinical applications. An IHC assay, Hercep Test $^{\mathrm{TM}}$, using the Dako polyclonal antibody A0485, was approved as an aid to the assessment of patients in whom Herceptin treatment is being considered. Two FISH assays were also approved as adjunct testsINFORM ${ }^{\mathrm{TM}}$ for the prediction of recurrence in patients with primary invasive, node negative breast carcinoma, and PathVysion ${ }^{\mathrm{TM}}$ for patients with stage II, node positive breast cancer, in particular for the response to adjuvant cyclophosphamide, doxorubicin, and 5-fluorouracil chemotherapy. For the critical evaluation of the usefulness of Her-2/neu tests in a clinical laboratory, we compared, for the first time, three commercially available assays - one IHC assay (using the widely used antibody A0485) and the two FISH assays, INFORM and PathVysion.

\section{Materials and methods}

SPECIMEN SELECTION AND PROCESSING

Specimens were obtained from consecutive mastectomies and breast core biopsies that were performed at the University of Texas Southwestern Medical Center at Dallas between August 1998 and January 1999. All specimens were fixed in $10 \%$ neutral buffered formalin and paraffin wax embedded. After microscopic diagnosis of infiltrating breast carcinoma, one representative tissue block from each patient was subjected to assessment of Her-2/neu status.

\section{IMMUNOHISTOCHEMISTRY}

The primary polyclonal anti-Her-2/neu antibody, A0485, was purchased from Dako Corporation (Carpenteria, California, USA). Buffers, blocking solutions, biotinylated polyvalent secondary antibodies, streptavidinbiotin complex reagents, chromagen, and haematoxylin counter stain were used as supplied in the Level 2 USA Ultrastreptavidin Multispecies Detection System (Signet Laboratories, Dedham, Massachusetts, USA). Antigen retrieval citra buffer was obtained from BioGenex (San Ramon, California, USA). Optimal dilutions of primary antibody (A0485) were predetermined as $1 / 3500$, using positive and negative Her-2 expressing breast cancer specimens. A known positive control section was included in each run to ensure proper staining.
All IHC staining was performed at room temperature on an automated BioTek solutions TechMate $^{\mathrm{TM}} 1000$ immunostainer (Ventana BioTek Systems, Tucson, Arizona, USA). Paraffin wax sections were cut at $3 \mu \mathrm{m}$ on a rotary microtome, mounted on positively charged POP100 capillary gap glass slides (Ventana BioTek Systems), and air dried overnight. Sections were then deparaffinised in xylene and ethanol. Sections were quenched with fresh 3\% hydrogen peroxide to inhibit endogenous tissue peroxidase activity for 10 minutes and rinsed with deionised water. Sections were then placed in $200 \mathrm{ml}$ antigen retrieval citra buffer, $\mathrm{pH} 6.8$, then brought up to the boil, after which $50 \mathrm{ml}$ of deionised water was added. The buffer was again boiled for five minutes. The slides were allowed to cool for 20 minutes and subsequently rinsed thoroughly in deionised water and then buffer. Sections were incubated in unlabelled blocking serum solution for five to 10 minutes and then incubated for 25 minutes with either primary antibody at a dilution of 1/3500 in buffer, or with buffer alone, as a negative reagent control. Subsequently, sections were washed in buffer, and then incubated first with biotinylated secondary antibody solution for 25 minutes and then horseradish peroxidase conjugated streptavidin-biotin complex for 15 minutes. Sections were washed in buffer, and then incubated with two changes, for five minutes each, of a freshly prepared mixture of diaminobenzidine (DAB) and $\mathrm{H}_{2} \mathrm{O}_{2}$ in buffer, followed by washing in buffer and then deionised water. Sections were then counter stained with haematoxylin, dehydrated in a graded series of ethanol and xylene, and covered with coverslips. Slides were viewed under the light microscope and photographed on a Nikon ECLIPSE E600 microscope (Nikon Instruments, Melville, New York, USA) with Quipps genetic workstation imaging software (Vysis Inc, Downers Grove, Illinois, USA). Positive reactions with $\mathrm{DAB}$ were identified as a dark brown reaction product on the cell membrane and the specimens were graded as negative, low, medium, and high positive, based on both the percentage of positively stained cells and the staining intensity (table 1). The specimens with high or medium IHC positivity were considered to have Her-2/neu overexpression, compatible with FDA approved criteria for Herceptin treatment.

\section{FLUORESCENCE IN SITU HYBRIDISATION}

For the INFORM assay, the commercial kit was purchased from Oncor Inc (Gaithersburg, Maryland, USA), which was subsequently acquired by Ventana Medical Systems (Tucson, Arizona, USA). The FISH assay was performed according to the manufacturer's recommended protocol after the laboratory received proficiency certification for performing the INFORM assay. Formalin fixed, paraffin wax embedded $4 \mu \mathrm{m}$ thick tissue sections were dried overnight in a $65^{\circ} \mathrm{C}\left( \pm 2^{\circ} \mathrm{C}\right)$ oven and then deparaffinised in xylene, followed by two changes of $100 \%$ ethanol. Sections were incubated in pretreatment solution (30\%) for 15 
Table 1 Criteria for Her-2/neu immunohistochemical assays

\begin{tabular}{ll}
\hline Interpretation & Microscopic findings \\
\hline Negative & $\begin{array}{l}\text { No immunostaining of cytoplasmic membrane identified } \\
\text { Faint or blush staining involving a portion of the circumference of the } \\
\text { cytoplasmic membrane in less than } 10 \% \text { of the neoplastic cell population } \\
\text { Weak but definitive staining of the membrane over } 100 \% \text { of the cytoplasmic } \\
\text { circumference in 11-30\% of the neoplastic cell population }\end{array}$ \\
Medium positive & $\begin{array}{l}\text { Strong positive staining of the membrane over } 100 \% \text { of the cytoplasmic } \\
\text { circumference in } 31-50 \% \text { of the neoplastic cell population }\end{array}$ \\
High positive & $\begin{array}{r}\text { Strong positive staining of the membrane over } 100 \% \text { of the cytoplasmic } \\
\text { circumference in } 51-100 \% \text { of the neoplastic cell population }\end{array}$ \\
\hline
\end{tabular}

Table 2 Criteria for Her-2/neu fluorescence in situ hybridisation assays

\begin{tabular}{|c|c|}
\hline Findings & Interpretation \\
\hline \multicolumn{2}{|c|}{$\begin{array}{l}\text { INFORM }{ }^{\mathrm{TM}}: 40 \text { randomly selected nuclei counted, if average } \\
\text { signals for each cell are: }\end{array}$} \\
\hline$\leqslant 4$ & Her-2/neu gene amplification not observed \\
\hline & \\
\hline \multicolumn{2}{|c|}{$\begin{array}{l}\text { PathVysion }{ }^{\mathrm{TM}} \text { : } 60 \text { randomly selected nuclei counted, if average } \\
\text { ratio of Her- } 2 / \text { neu signal to chromosome } 17 \text { centromere } \\
\text { signal is: }\end{array}$} \\
\hline$<2.0$ & \\
\hline$\geqslant 2.0$ & Her-2/neu gene amplification observed \\
\hline
\end{tabular}

minutes at $43^{\circ} \mathrm{C}\left( \pm 2^{\circ} \mathrm{C}\right)$ and digested in protein digesting enzyme solution for 40 minutes at $37^{\circ} \mathrm{C}\left( \pm 2^{\circ} \mathrm{C}\right)$. The slides were denatured in a $75^{\circ} \mathrm{C}$ water bath for eight minutes. The Her-2/neu unique sequence probe was warmed at $37^{\circ} \mathrm{C}$ for five minutes before application. A $10 \mu \mathrm{l}$ aliquot of the probe solution was pipetted on to the target tissue which was covered with a glass coverslip. The slides were hybridised at $37^{\circ} \mathrm{C}$ for $12-16$ hours in a humidified chamber. After removal of the coverslip, the sections were washed using a post-hybridization wash (20x saline sodium citrate (SSC) and formamide). Detection was then performed by indirect labelling of fluorescein tagged avidin, which binds to the DNA probe. The remainder of the genomic DNA, which was not bound by the DNA probe, was then stained with an interacting fluorescent counter stain (DAPI in antifade). Excitement of fluorescein and DAPI by light from a mercury arc lamp with appropriate filters in an epifluorescence microscope resulted in the emission of green and blue light for the Her-2/neu sequence and general genomic DNA, respectively. Specimens were evaluated with the Nikon ECLIPSE E600 microscope (Nikon Instruments, Melville, New York, USA) with Quipps genetic workstation imaging software (Vysis) under oil immersion at $\times 100$ magnification using the recommended filters. In each specimen, at least 40 cells were counted for Her-2/neu gene signals. The specimens with a mean fluorescence signal number of 4 or less for each cell were considered to be non-amplified, whereas those with a signal number of greater than 4 were considered to be

Table 3 Comparison of IHC with two FISH (INFORM ${ }^{\mathrm{TM}}$ and PathVysion ${ }^{\mathrm{TM}}$ ) assays

\begin{tabular}{|c|c|c|c|c|c|}
\hline & FISH & & & & Subtotal \\
\hline INFORM & Amplified & Amplified & Non-Amplified & Non-Amplified & \\
\hline PathVysion & Amplified & Non-Amplified & Amplified & Non-Amplified & \\
\hline \multicolumn{6}{|l|}{ IHC } \\
\hline High + & $10(19 \%)$ & 0 & 0 & $3(6 \%)$ & $13(25 \%)$ \\
\hline $\mathrm{Med}+$ & $3(6 \%)$ & $1(2 \%)$ & 0 & $9(17 \%)$ & $13(25 \%)$ \\
\hline Low + & $1(2 \%)$ & 0 & 0 & $8(15 \%)$ & $9(17 \%)$ \\
\hline $\mathrm{Neg}$ & 0 & 0 & 0 & $17(33 \%)$ & $17(33 \%)$ \\
\hline Subtotal & $14(27 \%)$ & $1(2 \%)$ & 0 & $37(71 \%)$ & $52(100 \%)$ \\
\hline
\end{tabular}

FISH, fluorescence in situ hybridisation; IHC, immunohistochemistry. amplified (table 2). Control slides supplied by Oncor were used as controls in each run of the assay.

For the PathVysion assay, the Her-2 DNA probe kit and the paraffin wax pretreatment reagent kit were purchased from Vysis. The FISH assay was performed according to the manufacturer's recommended protocol and after the laboratory received proficiency certification for performing the PathVysion assay. Briefly, formalin fixed, paraffin wax embedded tissues were cut into $4 \mu \mathrm{m}$ thick sections that were subsequently deparaffinised. Pretreatment, enzyme digestion, and fixation of the slides were performed. The slides were then denatured at $72^{\circ} \mathrm{C}\left( \pm 1^{\circ} \mathrm{C}\right)$ for five minutes. After a buffer wash, $10 \mu$ l of a mixture of two directly labelled probes - the Her-2/neu specific sequence probe (LSI HER-2/neu SpectrumOrange) and a probe for the $\alpha$ satellite sequence at chromosome 17 (CEP 17 SpectrumGreen) - were added to the tissue sections and hybridisation was carried out at $37^{\circ} \mathrm{C}$ for $14-18$ hours. The slides were then washed in a post-hybridisation wash, counter stained with DAPI, and covered with a coverslip. In each specimen, at least 60 cells were counted for both Her-2/neu gene and chromosome 17 centromere signals with a Nikon ECLIPSE E600 microscope (Nikon Instruments) with Quipps genetic workstation imaging software (Vysis) under oil immersion at $\times 100$ magnification using the recommended filters. The result is reported as the ratio of the average copy number of the Her-2/neu gene to that of the chromosome 17 centromere (CEP 17). Specimens with a signal ratio of less than 2.0 were designated as non-amplified and 2.0 or greater as amplified (table 2). Her-2/neu gene amplified and non-amplified tissues obtained from Vysis were used as controls.

\section{DATA ANALYSES}

For each specimen, two cytotechnologists independently analysed the data, using the respective manufacturer's recommended criteria. If a specimen received a score of 3.5 to 4.5 on the INFORM assay or 1.8 to 2.2 on the PathVysion assay, the assay was rescored. The pathologist then reviewed the case and finalised the diagnosis.

Statistical analyses were conducted on the 52 specimens that were subjected to all three Her$2 /$ neu assays. First, the three assays were grouped in a pairwise system so that any two of the three could be compared with each other. Cramer's $V$ and $\lambda$ were calculated for the three pairwise associations. Cramer's $\mathrm{V}$ is a $\chi^{2}$ based measure of association between two nominal variables and reduces to a $\pi$ coefficient when each nominal variable is dichotomous. Symmetric $\lambda$, a proportional reduction in error measure, provides a relative degree of association; $\lambda$ is considered more informative than the $\chi^{2}$ based measures because ratio comparisons can be performed between pairs of measures. Second, Cochran Q tests were performed to evaluate further whether these three assays make significantly different decisions; that is, generate different data. The Cochran $\mathrm{Q}$ test is 

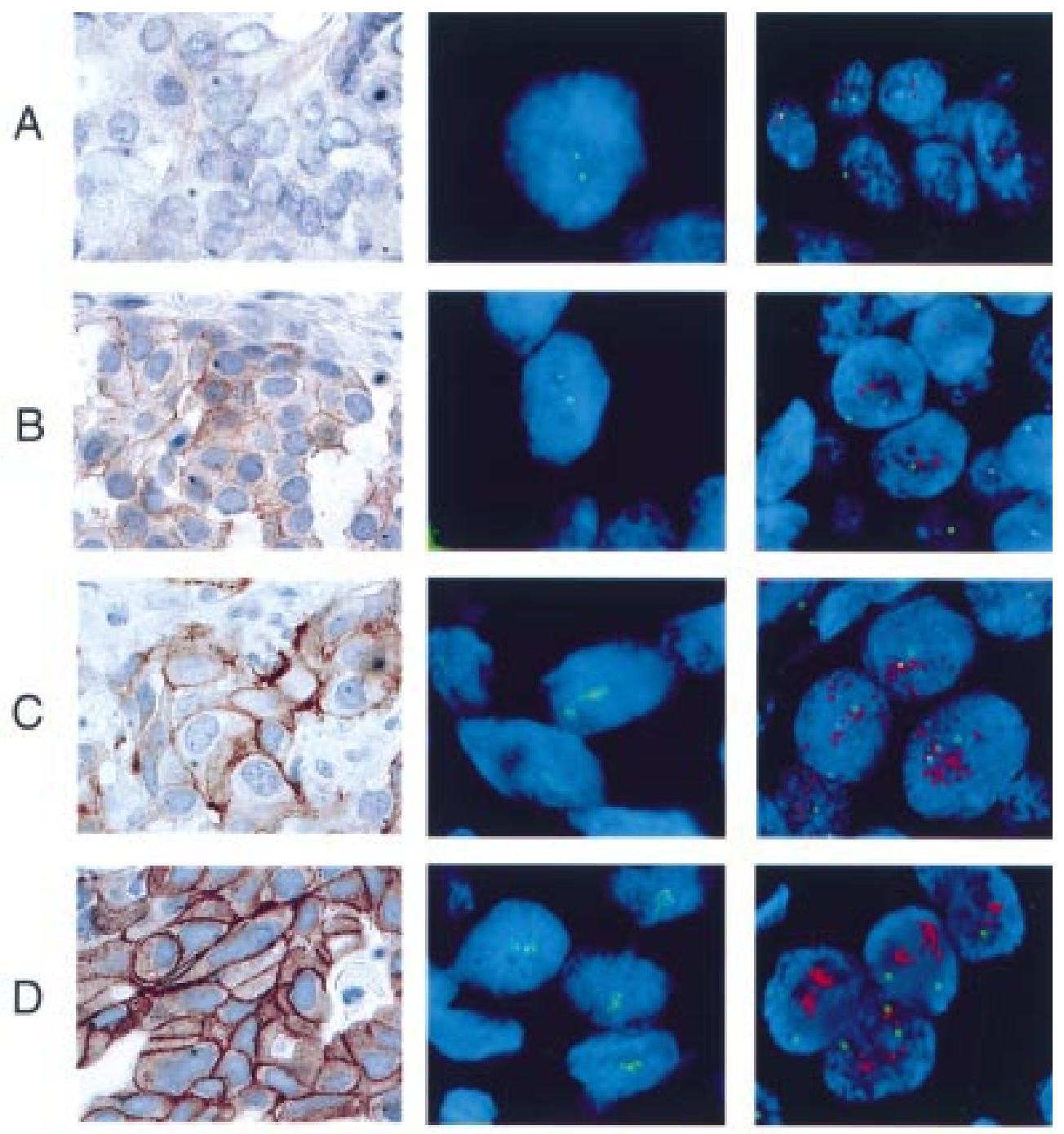

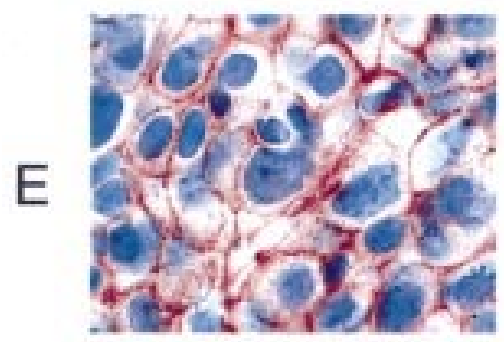

$\mathrm{IHC}$

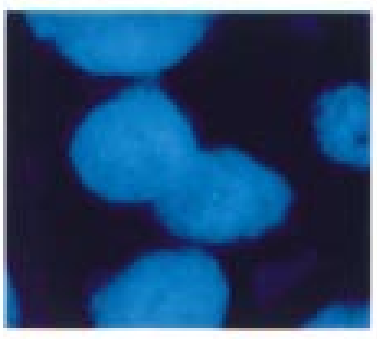

INFORM $^{\mathrm{TM}}$

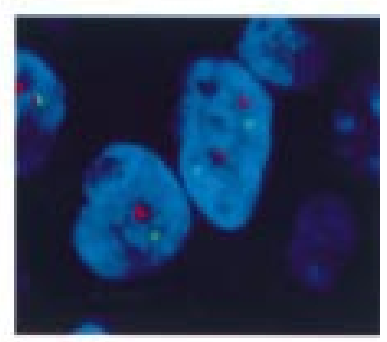

PathVysion ${ }^{\mathrm{TM}}$

Figure 1 Photomicrograph of the three assays. Representative cases are shown as follows: (A) Immunohistochemistry (IHC) negative and fluorescence in situ hybridisation (FISH; INFORM ${ }^{\mathrm{TM}}$ and PathVysion ${ }^{\mathrm{TM}}$ ) non-amplified; (B) IHC low positive and FISH (INFORM and PathVysion) non-amplified; (C) IHC medium positive and FISH (INFORM and PathVysion) amplified; (D) IHC high positive and FISH (INFORM and PathVysion) amplified; (E) IHC medium positive and FISH (INFORM and PathVysion) non-amplified.

a non-parametric test that examines whether $\mathrm{k}$ matched data sets differ significantly among themselves. Although the two FISH assays were already dichotomous-gene amplified versus non-amplified-the IHC data were not, they contained negative, low, medium, and high positive. Consequently, the IHC data were dichotomised in two possible group arrangements. In grouping 1 , high and medium positive results were placed in one subgroup, with low positive and negative in the other sub- group. In grouping 2, only high positive results were placed in one subgroup, with the other subgroup containing medium positive, low positive, and negative results.

\section{Results}

STUDY DESIGN AND SPECIMEN SELECTION

In the first step of this comparison study of IHC and FISH assays for Her-2/neu status, 84 consecutive specimens of invasive breast carcinoma from the University of Texas Southwest- 
Table 4 Comparison of two fluorescence in situ hybridisation assays: INFORM ${ }^{\mathrm{TM}}$ and PathVysion ${ }^{\mathrm{TM}}$

\begin{tabular}{llll}
\hline & & \multicolumn{2}{c}{ PathVysion } \\
\cline { 3 - 4 } & & Amplified & Non-amplified \\
\hline \multirow{2}{*}{ INFORM } & Amplified & $14(27 \%)$ & $1(2 \%)$ \\
& Non-amplified & 0 & $37(71 \%)$ \\
\hline
\end{tabular}

ern Medical Center at Dallas between August 1998 and January 1999 were submitted for IHC analysis. In the second step, the specimens were stratified, based on the IHC assay determined Her-2/neu protein values, into four groups: high positive (23 specimens, $27 \%$ total), medium positive (24 specimens, 29\% total), low positive (14 specimens, $17 \%$ total), and negative (23 specimens, $27 \%$ total). In an effort to control the size of the study, a subset of 52 specimens was selected randomly from each group for the subsequent two FISH assays.

IHC AND FISH ASSAYS FOR HER-2/NEU STATUS Table 3 shows the results from all three Her-2/ neu assays. Based on the criteria of the IHC assay (table 1), the selected 52 specimens contained variable amounts of Her-2/neu protein, and comprised 13 high positive specimens (25\%), 13 medium positive specimens (25\%), nine low positive specimens (17\%), and 17 negative specimens (33\%) (fig 1). The percentage of Her-2/neu positive specimens, including high and medium positive specimens, was $50 \%$.

However, subsequent FISH assays of the same specimens revealed rather different data for $\mathrm{Her}-2 /$ neu gene amplification (table 4 ). Of the 52 cases, 14 specimens $(27 \%)$ were positive for Her-2/neu gene amplification by both INFORM and PathVysion, 37 specimens (71\%) negative by both INFORM and PathVysion, and one specimen (2\%) positive by INFORM, but negative by PathVysion. The percentage of cases with Her-2/neu gene amplification, $27 \%$, is consistent with most previously published reports. It is also important to note that the two FISH assays have a highly significant association- 51 of the 52 cases $(98 \%)$ gave the same results by both FISH assays. The only specimen showing disagreement between the FISH assays appeared to be a borderline case, with the raw scores of 1.50 by PathVysion and borderline 4.38 by INFORM.

Interestingly, comparison of the IHC and FISH assays reveals that FISH (INFORM and PathVysion) negative cases can be further divided into three ( $6 \%$ total) IHC high positive cases, nine ( $17 \%$ total) IHC medium positive cases, eight (15\% total) IHC low positive cases, and $17(33 \%)$ IHC negative cases (table 3). In other words, 12 (23\% total) of 26 (50\% total)

Table 5 Statistical comparison of the three Her-2/neu assays in pairs

\begin{tabular}{llll}
\hline Pairwise correlation & IHC v INFORM & IHC v PathVysion & $\begin{array}{l}\text { INM } \\
\text { PathVysion }\end{array}$ \\
\hline Cramer's V test (p value) & $0.664(<0.0001)$ & $0.680(<0.0001)$ & $0.955(<0.0001)$ \\
$\lambda$ Test (p value) & $0.340(0.005)$ & $0.347(0.005)$ & $0.935(<0.0001)$ \\
\hline
\end{tabular}

Table 6 Statistical comparison of the three Her-2/neu assays as a group

\begin{tabular}{lcl}
\hline Dichotomised groupings & Cochran's $Q$ & p Value \\
\hline Grouping 1 & 19.000 & $<0.001$ \\
Grouping 2 & 0.375 & $>0.05$ \\
\hline
\end{tabular}

IHC high or medium positive cases showed no gene amplification by both FISH assays (fig 1E).

STATISTICAL ANALYSES

Statistical analyses first compared any two of the three assays in a pairwise fashion. All three pairwise associations by Cramer's $V$ and $\lambda$ calculation were found to be significant (table 5). Although these results indicate that the three assays are significantly related to one another, there seems to be a quantitative difference between IHC and the two FISH assays. The use of $\lambda$ analysis revealed that the association between the two FISH assays was three times higher than the association between IHC and either one of the two FISH assays, suggesting that the results of the two FISH assays were more closely associated with each other than those of IHC and one of the two FISH assays.

To investigate further the relation between the three assays, the Cochran Q test was used. This test revealed that the difference among the three sets of matched assays (IHC, INFORM, or PathVysion) was significant in grouping 1 , which separated the cases by IHC determined Her-2/neu protein levels into one subgroup of high and medium positive and the other subgroup of low positive and negative. In contrast, there was no significant difference in grouping 2, which separated the cases by Her$2 /$ neu protein levels into one subgroup of high positive and the other subgroup of medium positive, low positive, and negative (table 6). The only variable between groupings 1 and 2 was the Her-2/neu medium positive cases, which in grouping 1 were in the same subgroup as the high positives, but in grouping 2 were in the other subgroup with low positives and negatives. This analysis highlights the importance of such Her-2/neu medium positive cases because grouping 1 resulted in nonequivalent assessment of Her-2/neu status across the three assays, whereas grouping 2 resulted in equivalent assessment of $\mathrm{Her}-2 /$ neu status.

\section{Discussion}

In our study, we evaluated the clinical usefulness of three Her-2/neu assays side by side in 52 infiltrating breast carcinoma specimens. To our knowledge, this is the first study to compare the IHC assay using the Dako polyclonal antibody, A0485, with the two FDA approved FISH assays, INFORM and PathVysion. Statistical analyses of our results revealed that all three assays are related to each other, supporting the validity of these tests. However, we encountered some issues that might have important implications in future assessment of Her-2/neu status for the clinical management of breast cancer, as well as in understanding the mechanism of Her-2/neu gene expression. 
IHC assays are simple and inexpensive to perform in a clinical laboratory setting. However, because IHC evaluates the amounts of Her-2/neu protein in individual cells, there are many variables that could potentially complicate the interpretation of results. For example, because Her-2/neu is expressed in normal epithelial cells, there is the problem of background staining. In addition, because the protein is unstable, variations in tissue fixation and processing could affect the final results of the assay. Moreover, laboratories use numerous anti-Her-2/neu antibodies, either polyclonal, such as the widely used A0485, or monoclonal, which all have varying sensitivities and specificities. ${ }^{17}$ Perhaps the most important factor is that an arbitrary scoring system needs to be assigned for Her-2/neu protein levels, which in reality cover a continuous spectrum. In fact, different scoring systems have been used. Our recent pilot study and our current study used graded values, including high, medium, and low positive and negative, ${ }^{18}$ whereas HercepTest used $3+, 2+, 1+$, and negative. However, other studies have used strong positive $(2+)$, weak positive $(1+)$, and absent $(0),{ }^{19}$ or a positive versus negative system, where "positive" was defined as the relative difference in cytoplasmic membrane staining between tumour cells and normal epithelial cells. ${ }^{20}$ Therefore, it is inevitable that some interlaboratory discrepancies may exist for at least some of the cases, especially medium or low positive ones. This type of inconsistency could cause difficulties in clinical management, such as deciding whether to give Herceptin treatment.

In contrast, FISH assays are a new genetics based technology and have been used predominantly in research and cytogenetics laboratories. FISH assays are time consuming and more expensive because individual cells need to be evaluated one at a time, unlike IHC, in which an area of tumour cells is evaluated collectively. FISH also requires special equipment, such as a fluorescence microscope, and laboratory personnel training. However, the FISH assay might be intrinsically more reproducible and consistent. DNA is very stable, thus much less susceptible to variations in tissue fixation processing. Moreover, because the definition of positivity is based on distinct signals in a cell, which represent chromosomal regions containing the amplified Her-2/neu gene, it is less arbitrary and subjective than the IHC grading scale. In our study, the FISH assays, INFORM and PathVysion, had a concordance of $98 \%$ identical results were seen in 51 of 52 cases, with disagreement in only one case $(2 \%)$. If such consistency can be reproduced in other laboratories, FISH assays could prove to be truly valuable in clinical practice. Of these two FISH assays, PathVysion has two distinct advantages over INFORM. One is that the use of direct probe labelling in PathVysion significantly reduces non-specific cellular staining, which is commonly seen as a result of the indirect labelling used in the INFORM assay. The other advantage is that PathVysion uses an internal control probe for the chromosome 17 centromere region to differentiate specific Her-2/neu gene amplification from chromosome 17 polysomy (fig 1 ).

Perhaps the most intriguing finding of our study was the significantly different results seen for the IHC and FISH assays. When IHC high and medium positive cases are considered to have Her-2/neu overexpression, compatible with FDA recommended criteria for Herceptin treatment, 26 of the 52 cases ( $50 \%$ of total) are found to overexpress this oncoprotein. These 26 cases comprise 13 ( $25 \%$ of total) high positive cases and 13 (25\% total) medium positive cases, and these results are significantly higher than $25-30 \%$ of $\mathrm{Her}-2 /$ neu overexpression cases in many published reports..$^{3-5}$ In contrast, only 14 cases $(27 \%$ of total) showed Her- $2 /$ neu gene amplification by both FISH assays. Because IHC and FISH assays measure related, but distinct targets-protein concentrations versus gene copies-it is expected that they might show some disagreement, particularly in cases with high concentrations of the Her-2/neu protein without concurrent gene amplification. However, most published reports found this disagreement in less than $10 \%$ of specimens, or in as few as 3\% of the Her-2/ neu overexpressing cases. ${ }^{21}$ Furthermore, statistical analysis by the Cochran $\mathrm{Q}$ test revealed that the IHC medium positive but FISH negative cases were the main subgroup contributing to the disagreement. We cannot rule out the possibility that these cases truly overexpress Her-2/neu protein without gene amplification, because the number of cases is relatively small and there are no independent definitive assays to measure Her-2/neu protein concentrations and gene copies in individual cells. However, other factors are more likely to have played crucial roles. As discussed above, the IHC assay is intrinsically more variable, particularly in specimen processing and antigen retrieval. Another possibility is that because FISH assays use 4 signals in each nucleus as positive for gene amplification, or a ratio of 2 , some of the cases with low gene amplification might not have been scored as amplified, thus underestimating gene amplification. Alternatively, polysomy 17, with a corresponding increase in Her2/neu gene copies does not qualify for Her2/neu gene amplification based on FISH criteria, but it could still potentially cause Her2/neu gene overexpression.

Two recent studies highlighted the complexity of using the IHC assay for the assessment of Her-2/neu status. Both studies used the same Dako polyclonal anti-Her2 antibody, but yielded dramatically different results. A study at the Mayo Clinic showed that $60 \%$ of 117 breast cancer cases in a Mayo Clinic intramural cohort overexpressed Her-2/neu, with values of $2+$ or $3+$, (similar to medium or high positive values in our study), and $57 \%$ of 1142 breast cancer cases in an extramural cohort had values of $2+$ or $3+\mathrm{Her}-2 / \mathrm{neu}^{22}$ These results are comparable with $50 \%$ of high and medium positive cases in our study. In the same Mayo Clinic study, the Dako HercepTest kit containing the same A0485 antibody detected a similar high percentage of Her2/neu overexpres- 
sion, whereas a different monoclonal anti-Her2 antibody, CB11, detected only $26 \%$ of the cases overexpressing Her-2/neu, thus suggesting that the specificity of the primary antibody might be a key factor. Independently, Jacobs et al reported rather different results in a comparison study of the IHC assay using the Dako A0485 antibody and the INFORM FISH assay. ${ }^{23}$ In the study of 100 consecutive invasive breast cancers, $23 \%$ and $26 \%$ of the interpretable cases showed Her- $2 /$ neu protein overexpression and Her- $2 /$ neu gene amplification, respectively, with $91 \%$ concordance. However, the study used a novel scoring system for the IHC assay, as reported previously ${ }^{20}$; that is, a 0 to $4+$ scale that defined cases as overexpressing the Her-2/neu protein if the specimen showed an absolute score of $3+$ to $4+$ in tumour cells or if the difference between the score of the tumour cells and the score of the surrounding normal epithelial cells was $2+$ or greater. This 0 to $4+$ scale is different from the 0 to $3+$ scale used in the evaluation of eligibility for Herceptin treatment, which is recommended by the manufacturer of A0495, Dako Corporation. It appears that such subtraction is useful only when there is a problem with background staining, although this report did not specifically discuss how many cases were subjected to subtraction.

Another important, albeit controversial, factor with regard to the choice of assay for the evaluation of Her-2/neu status is the cost for each assay. IHC using a commercially available antibody, such as Dako A0485, is probably the least expensive test; IHC in a kit form, such as the Dako HercepTest, is in the middle range; and FISH assays are more expensive. Although the cost should be a long term concern, the most important task for the laboratory service is to provide consistent and reliable information on Her- $2 /$ neu status. When taking into account the rapidly increasing importance of such molecular biomarkers as the Her-2/neu oncogene/oncoprotein, the related high cost of Herceptin or other treatments, and the potential clinical benefits, the cost differential between Her-2/neu assays ${ }^{23}$ should not be an important factor, especially at the current stage when the clinical application and correlation of these assays is just beginning to be evaluated extensively. In fact, our experience showed that with good initial training and additional equipment, a pathology laboratory could perform FISH assays very efficiently and reliably.

In summary, our study evaluated the clinical usefulness of the three Her-2/neu assays. In agreement with other reports, ${ }^{21-23}$ we confirmed the validity of these assays, but also demonstrated that numerous factors might affect the final results. It is evident that the assessment of Her-2/neu status should use widely available reagents and a standardised scoring system to ensure accuracy of measurement and interlaboratory consistency. In addition, clinical correlation is crucially needed with regard to which assay provides best prognostic and predictive value. Because these assays evaluate Her-2/neu status by measuring distinct, but related, targets and the FDA has approved these assays for different clinical applications, we believe the best approach at the present time is to divide the evaluation of Her-2/neu status into two steps. In the first step, IHC with Dako A0485 antibody is used as an initial triage assay. In the second step, PathVysion FISH assay is used to analyse the IHC high or medium positive cases so that corroboration between IHC and FISH may be achieved. While the Her-2/neu assays are being perfected, such a combinatorial strategy should provide comprehensive and valuable information on both Her-2/neu protein concentrations and gene amplification to help clinicians make crucial management decisions.

Note added in proof: Some recent studies of breast cancer specimens also showed a high percentage of $2+$ IHC staining for Her-2/neu protein using Dako's Hercep Test ${ }^{24}$ or Dako's polyclonal antibody and some other antibodies. $^{25}$

We acknowledge the invaluable technical assistance of F Saliger and S Thomas, division of cytopathology, Parkland Memorial Hospital who performed the fluorescence in situ hybridisation assays. We thank the immunohistochemistry laboratory at the University of Southwestern Medical Center for performing the immunohistochemistry assay. We also thank T Dixon for the preparation of this manuscript. Presented in part at the 89th annual meeting of the United States and Canadian Academy of Pathology, March 25-31, 2000

1 Alroy I, Yarden Y. The ErbB signaling network in embryogenesis and oncogenesis: signal diversification through combinatorial ligand-receptor interactions. FEBS Lett 1997;410:83-6.

2 Reese D, Slamon DJ. HER-2/neu signal transduction in human breast and ovarian cancer. Stem Cells (Dayt) 1997; $15: 1-8$

3 Slamon DJ, Clark GM, Wong SG, et al. Human breast cancer: correlation of relapse and survival with amplificaion of the HER-2/neu oncogene. Science 1987;235:17781 .

4 Slamon DJ, Godolphin W, Jones LA, et al. Studies of the $\mathrm{Her} /$ neu proto-oncogene in human breast and ovarian cancer. Science 1989;244:707-12.

5 Revillion F, Bonneterre J, Peyrat JP. ERBB2 oncogene in human breast cancer and its clinical significance. Eur $\mathcal{F}$ Cancer 1998;34:791-808.

6 Naber SP, Tsutsumi Y, Yin S, et al. Strategies for the analysis of oncogene overexpression. Studies of the neu oncogene in breast carcinoma. Am f Clin Pathol 1990;94: 125-36.

7 Kallioniemi O-P, Kallioniemi A, Kurisu W, et al. ERBB2 amplification in breast cancer analyzed by fluorescence in amplification in breast cancer analyzed by fluorescence in 5 .

8 McGann AH, Dervan PA, O'Regan M, et al. Prognostic significance of c-erbB-2 and estrogen receptor status in human breast cancer. Cancer Res 1991;51:3296-303.

9 Gusterson, BA, Gelber RD, Goldhirsch A, et al. Prognostic importance of c-erbB-2 expression in breast cancer. $\mathcal{F}$ Clin Oncol 1992;10:1049-56.

10 Quenel N, Wafflart J, Bonichon F, et al. The prognostic value of c-erbB2 in primary breast carcinomas: a study on 942 cases. Breast Cancer Res Treat 1995;35:283-91.

11 Press MF, Bernstein L, Thomas PA, et al. HER-2/neu gene amplification characterized by fluorescence in situ hybridization: poor prognosis in node-negative breast carcinomas. f Clin Oncol 1997;15:2894-904.

12 Allred DC, Harvey JM, Berardo M, et al. Prognostic and predictive factors in breast cancer by immunohistopredictive factors in breast cancer by im
chemical analysis. Mod Pathol 1998;11:155-68.

13 Muss HB, Thor AD, Berry DA, et al. C-erbB-2 expression and response to adjuvant therapy in women with node-positive breast cancer. N Engl F Med 1994;330:12606.

14 Carter P, Presta L, Gorman CM, et al. Humanization of an anti-p185HER2 antibody for human cancer therapy. Proc Natl Acad Sci U S A 1992;89:4285-9.

15 Baselga, J, Norton L, Albanell J, et al. Recombinant humanzed anti-HER2 antibody (Herceptin) enhances the antitumor activity of Paclitaxel and doxorubicin against HER2/neu overexpressing human breast cancer xenografts. Cancer Res 1998;58:2825-31.

16 Slamon DJ, Leyland-Jones B, Shak S, et al. Addition of Herceptin (humanized anti-HER2 antibody) to first line chemotherapy for HER-2 overexpressing metastatic breast cancer (HER2+/MBC) markedly increases anti-cancer activity: a randomized, multinational controlled phase III trial [abstract 377]. Proceedings of the American Society of trial [abstract 377]. Proceedings
Clinical Oncology 1998;17:98A. 
17 Press MF, Hung G, Godolphin W, et al. Sensitivity of HER2/neu antibodies in archival tissue samples: potential source of errors in immunohistochemical studies E. Cancer Res $1994,54: 2771-77$.

18 Ashfaq R, Frenkel E, Saliger F, et al. Her-2/neu oncogene overexpression: comparison of immunohistochemistry (IHC) with fluorescent in situ hybridization assay (FISH) [abstract 70]. Mod Pathol 1999;12:15A.

19 Jimenez RE, Wallis T, Tabaczka P, et al. Fluorescent in situ hybridization (FISH) vs immunohistochemistry (IHC) for determination of Her2/neu status in breast cancer [abstract 116]. Mod Pathol 1999;12:23A

20 Jacobs TW, Barnes M, Yaziji H, et al. Her2/neu protein expression in breast cancer determined by immunohistochemistry (IHC): a study of inter-laboratory agreement [abstract 113]. Mod Pathol 1999;12:23A.

21 Pauletti G, Godolphin W, Press MF, et al. Detection and quantitation of HER-2/neu gene amplification in human breast cancer archival material using fluorescence in situ hybridization. Oncogene 1996;13:63-72.

22 Roche PC, Ingle JN. Increased HER2 with US Food and Drug Administration-approved antibody. $\mathcal{f}$ Clin Oncol 1999;17:434-435.

23 Jacobs TW, Gown AM, Yaziji H, et al. Comparison of fluorescence in situ hybridization and immunohistochemistry for the evaluation of HER-2/neu in breast cancer. 7 Clin Oncol 1999;17:1974-82.

24 Jacobs TW, Gown AM, Yaziji H, et al. Specificity of Hercep Test in determining HER-2/neu status of breast cancers using the United States Food and Drug Administrationapproved scoring system. F Clin Oncol 1999;17:1983-7.

25 Jimenez RE, Wallis T, Tabasczka P, et al. Determination of Her-2/Neu status in breast carcinoma: comparative analysis of immunohistochemistry and fluorescent in situ hybridization. Mod Pathol 2000;13:37-45.

\section{PATHOLOGY INTERACTIVE 2000}

\section{Do you know ....?}

\section{Pathology Interactive Volume 2 now offers:}

Up to three CPD credits per review article

1 credit for reading the article and completing the associated questions

1 credit for additional reading, following up references

1 credit for making notes, identifying learning outcome or identifying further learning needs

CPD credits for working on articles outside your specialty

\section{Pathology Interactive Volume 2 Issue 1 includes articles in:}

Microbiology

Histopathology

Molecular pathology

\section{Further issues in $\mathbf{2 0 0 0}$ will cover further articles in these specialties, plus:}

Chemical pathology

Haematology

Immunology

Including case study and picture quiz formats

Pathology Interactive 2000 Volume 2, 4 issues (March, June, September, December) ISSN 14665743 Accredited by the Royal College of Pathologists

Subscription rate: $£ 75+$ VAT personal ${ }^{\star}, £ 150+$ VAT institutional (multiuser rate on application to the publisher).

Send orders to: BMJ Publishing Group, Journals Marketing Dept. PO Box 299, London WC1H 9TD, UK; fax credit card orders to: +44 (0)20 7383 6402; call subscriptions hotline +44 (0)207383 6270; email orders to: subscriptions@bmjgroup.com

*ACP members receive Pathology Interactive with their copy of fournal of Clinical Pathology, as a membership benefit. 